\title{
SELVASAPARA.COM Una plataforma web sobre la memoria y la vida de un grupo de Saparas del Ecuador
}

\author{
Rafaela Palacios \\ Casandra Sabag \\ Paúl Narváez Sevilla
}

S ELVASAPARA.COM es una plataforma web construida y pensada como una herramienta de educación y difusión de la memoria de cuatro comunidades saparas de la Amazonía ecuatoriana. Es una interpretación multimedia de la vida de un grupo de hombres y mujeres que hoy protegen su territorio de la llegada de dos pozos petroleros que ponen en peligro conocimientos medicinales milenarios, la lengua sapara y la vida de esta selva única en el mundo.

Este proyecto tiene como antecedente la plataforma web sobre conocimientos médicos y botánicos de una abuela del Cañar-Ecuador: www.unjardinpropio.com. Ante la reacción positiva del público a este primer proyecto, vimos la importancia de ampliarlo a otras zonas geográficas para motivar el debate sobre la valoración de los conocimientos y memorias de los pueblos de la Amazonía ecuatoriana.

Escribimos el proyecto y ganamos uno de los fondos que otorga el Premio Nacional Mariano Aguilera. Buscamos aliados y nos encontramos con Naku, un programa que se interesa en "compartir conocimientos ancestrales, costumbres, historias, alimentos y vivencias en medio del bosque sapara". Con apoyo de Naku y del Premio Nuevo Mariano Aguilera ingresamos a la selva sapara: Rafaela Palacios Correa, Casandra Sabag Hillen y Paúl Narváez Sevilla. Ahí trece mujeres y hombres de las comunidades de Matsakaw, Naruka, Akachinia y Llanchamacocha nos compartieron sus conocimientos y memorias. También trabajamos con los niños y niñas de la escuela de Llanchamacocha quienes nos enseñaron algunas canciones en lengua sapara y ayudaron a construir la sección de "Palabra sapara" y "El sonido de la selva".

Actualmente varias comunidades saparas cuentan con servicio de internet financiado por la organización internacional Amazon Watch. Los habitantes de estas comunidades pueden acceder a la plataforma y usarla como material educativo y recreativo.

Una de las motivaciones para construir este proyecto fue que las memorias del pueblo sapara han sido vagamente registradas. Aún se sabe muy poco de su historia hasta el punto de que por décadas se les creyó extintos (Castillo et al., 2016). El día de hoy, los saparas habitan parte de la Amazonía de Ecuador y Perú. En Ecuador su territorio está en la provincia de Pastaza y cubre una extensión aproximada de 360.000 hectáreas.

Las crónicas cuentan que en 1659 su territorio era más extenso, eran nómadas y la lengua sapara era hablada por 25 mil personas (Moya, 2007). Las enfermedades traídas por los españoles mataron a miles, la esclavitud por la explotación del caucho (1890-1920) exterminó a muchas comunidades y en la guerra entre Ecuador y Perú de 1941 fueron separadas y asesinadas varias familias. 
En 1980 decidieron asentarse y crear comunidades sedentarias como una estrategia para proteger el territorio de amenazas como la explotación petrolera (Castillo et al., 2016). Actualmente viven aproximadamente 600 saparas en territorio ecuatoriano, sólo tres ancianos recuerdan su lengua y en su territorio existen dos bloques petroleros 79 y 83 concesionados a la empresa China Andes Petroleum.

La lucha actual de muchas de las comunidades gira en torno a la defensa de su territorio y está ligada directamente con la relación que tienen los saparas con los espíritus de la selva. Para ellos el pétroleo es un espíritu muy poderoso, vital para el equilibrio de su tierra. En una entrevista en la comunidad de Llanchamacocha, Clemente Ushigua, habitante y guía en esta investigación nos explicó: "el petróleo también tiene su espíritu, el petróleo es quien da vida, nutrientes y fuerza a las plantas, por eso no queremos que nos saquen el petróleo, él es el poder de la selva, de los animales, de las plantas, de las montañas".

Los bloque petroleros concesionados ocuparían el $90 \%$ del territorio sapara y un solo derrame pondría en peligro una de las mayores reservas de bosques amazónicos del planeta. Lo paradójico de estas concesiones es que el Ecuador es el primer y único país en el mundo en proclamar a la naturaleza como sujeto de derechos en su Constitución. A pesar de ello, el plan de explotación avanza, yendo en contra del deseo de sus pobladores y de este bosque único en el mundo. Afortunadamente un grupo de saparas están luchando a nivel nacional e internacional y, por ahora, han logrado detener la expansión petrolera de su territorio.

Al defender la selva también están defendiendo sus memorias y aquí cabe la pregunta: ¿Qué significa la memoria para un pueblo en riesgo de desaparecer?

Las memorias grabadas en audio fueron la principal fuente de información e hilo narrativo de esta plataforma web. Entendimos que registrar sus testimonios pensando que estos serían escuchados por los niños y niñas de la escuela de Llanchamacocha era una de las decisiones políticas y estéticas que más podrían ayudar a las comunidades. Compartir recuerdos de esta cultura milenaria como acto político y poético.

Los ancianos saparas cuentan que cuando eran niños los adultos inhalaban agua de tabaco y reunían a los jóvenes para contarles historias sobre tiempos antiguos. Los relatos explicaban todo lo que había que saber para vivir en la selva: la dinámica entre humanos plantas y animales, la relación entre el mundo físico y el mundo espiritual de la selva, las guerras inter-étnicas y otros elementos. La memoria oral como la forma de trasmitir conocimiento.

El recordar es la primera actividad diaria que realizan los saparas, incluso antes de su primera comida. Cada mañana al despertar se preguntan unos a otros ¿imashina pagarirankichu? (¿recuerdas lo que soñaste?). Ese ejercicio de memoria es trascendental, ya que según lo que soñaron planifican su día. Deciden salir de cacería, de pesca o quedarse cerca de su casa a trabajar en la huerta. Los saparas cuentan que en sus sueños pasean por el mundo espiritual. Ahí conversan con animales, plantas y antepasados que les dan información sobre el mundo físico. Con ayuda de algunas plantas, padres y madres preparan a sus hijos para ser "buenos soñadores". El buen soñador recuerda e interpreta sus sueños.

Uno de los relatos que más nos impactó fue el de Mukutsawa, una de las tres ancianas que aún recuerda algo de la lengua sapara y que nos explica a través de un sueño que tuvo cómo la vida onírica decide en muchos casos la vida material:

"Yo estaba cerca del río y vi un venado. Le apuñalé para matarlo y llevármelo a comer. En la noche soñé que el venado se convertía en un hombre grande y me desafiaba a pelear. Yo le di un puñetazo y le empujé al suelo, él se recuperó, le volví a pegar y lo tenía agarrado del cuello. El venado se dio cuenta de que yo soy fuerte y me dijo: 'Tú me has vencido, ya no peleemos seamos amigos. Te pido que no me mates ni comas mi carne hasta el día en que mueras. En cada venado que veas yo estaré ahí'. Así soñé, por eso ahora no como carne de venado, si como me enfermo. Así son los sueños." 

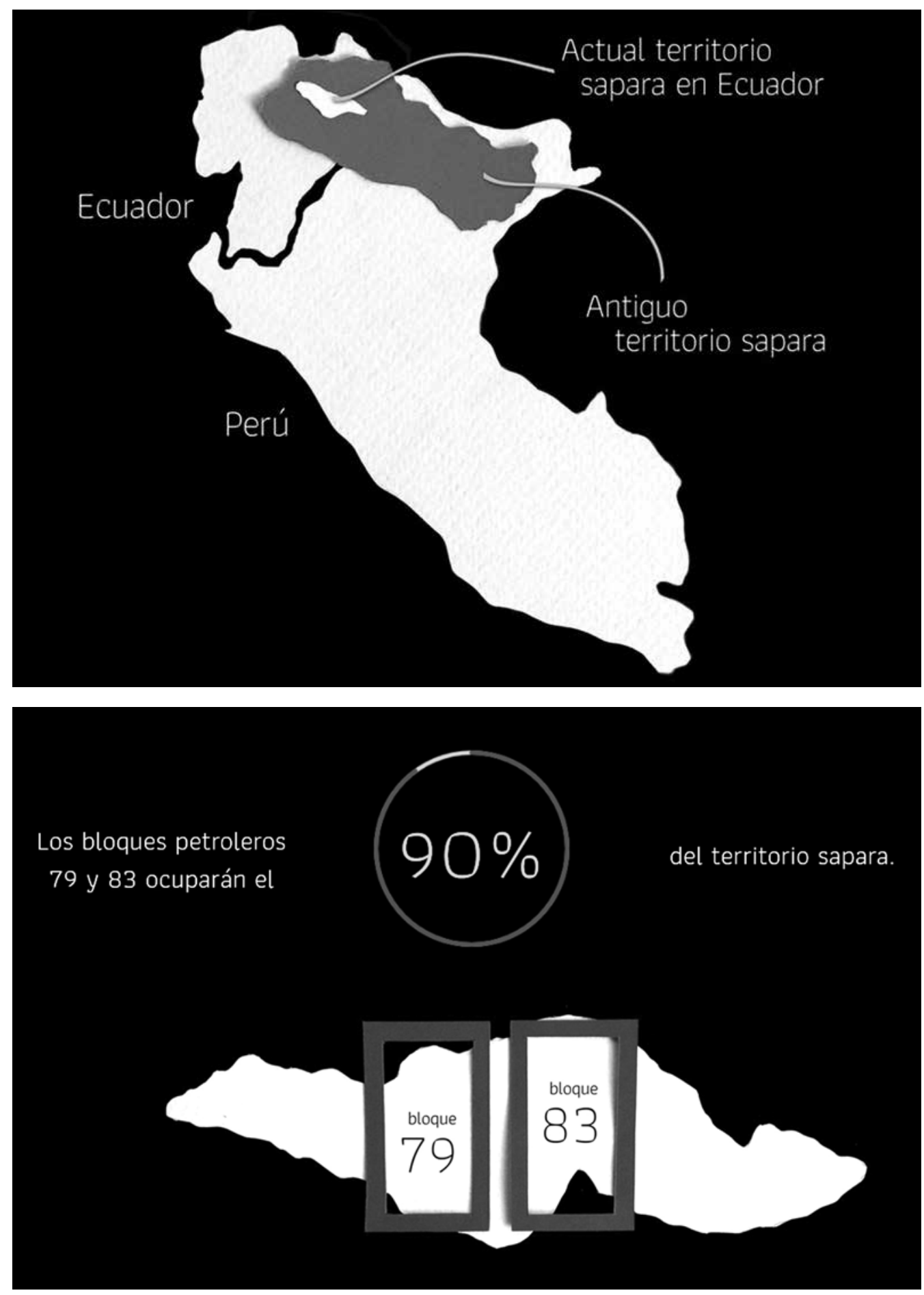
La plataforma cuenta con ocho narrativas principales y partió de un análisis antes de salir al trabajo de campo y durante la estadía en la población de Llanchamacocha. Partimos el análisis entendiendo que la pantalla se ha hecho mundo, un espacio privado y público que hoy en día permite repensar lo material, el territorio y su reposicionamiento político y estético. Pensamos que el internet es un vehículo político. De tal forma, que no podíamos pensar de otra forma su estética. Así las narrativas hipermedia en esta plataforma buscan potencializar la voz de las memorias de quienes tuvimos contacto en su forma literal, en forma de sonidos, testimonios; y simbólica, desde las sensaciones y la imaginación.

Esta plataforma es una puesta en escena. Esa era la apuesta. Los "muñequitos" que aparecen en la plataforma con delicados cortes de papel de algodón representan nuestra interpretación. Una interpretación que debíamos transparentar como una mediación no neutral, entre los conocimientos y memorias de los saparas, la hipermedia y los posibles usuarios. Para ellos tomamos varias decisiones.

En primer lugar, quisimos alejarnos de la imagen fotográfica por su carga histórica hacia la verisimilitud. Por un lado, teníamos los modelos de representación heredados de la antropología tradicional del siglo XIX, que miraba desde el lente con exotismo y distancia al otro. De ahí, decidimos no mostrar una imagen que pretendiera realidad y/u objetividad.

Por el otro lado, contábamos con el modelo de representación construida desde el imaginario del turismo, idealizada, "limpiada" perfecta para experiencias garantizadas. Para alejarnos de ambos cánones visuales, decidimos no mostrar ninguna representación fotográfica de las personas que participamos en el proyecto. Todo sujeto sería representado como un personaje de papel. Aludiendo, de nuevo a tres voces que desde mecanismos audiovisuales construían un mundo, un mundo ficticio.

Otra decisión, fue la cromática. Elegimos el rojo por ser antítesis del "color selva": el verde. El rojo con sus atributos sensoriales, ópticos e iconográficos, resolvía la construcción de atención en el usuario al ser un color que atrapa a la pupila, que provoca perceptivamente calor y un color político en occidente. No nos interesaba recurrir al imaginario colmado de verde de la amazonía. Eso ya estaba en la mente de los usuarios occidentales. Necesitábamos de su imaginación para completar y recrear una selva particular.

El papel de algodón para la construcción de los "muñequitos" de la plataforma se eligió por una apuesta que el Sindicato Audiovisual porta, como colectivo, desde sus inicios. La interacción entre el lenguaje análogo y el digital, lo manual frente a las innovaciones tecnológicas. Una estética en diálogo. Buscábamos un acercamiento a la sinestesia, respetando la textura, volumen y temperatura del papel frente a su soporte digital, plano y frío. Además, el papel de algodón, si bien es orgánico, está construido bajo un proceso occidental. Es decir que, era coherente con nuestra postura. La materialidad de los objetos hablada de la posición desde la que hablábamos como portadores de memorias de una comunidad a la que no pertenecíamos, pero que, sin embargo, podía por sus cualidades físicas y estéticas interpretarla de forma amigable.

Cabe mencionar que, mientras estábamos en el trabajo de campo en la comunidad de Llanchamacocha comenzamos el diseño y corte de estos "muñequitos". Algunas personas de la comunidad mostraron curiosidad, incluso el profesor de la escuela, al ver los procesos creativos de la transformación del papel, nos extendió la invitación para visitar a sus estudiantes y realizar algunas actividades en las que los niños dibujaron y compartieron canciones que, posteriormente, serían integradas al proyecto hipermedia. El papel de nueva cuenta fungió como un puente de interpretación.

Creemos que las nuevas tecnologías tienen un poder narrativo que puede ser usado para poner en discusión pública temas fundamentales en los tiempos actuales. Con este proyecto buscamos abrir el debate sobre la importancia de los conocimientos médicos ancestrales del pueblo sapara, de la importancia de los sueños para la vida material y de la necesidad de repensar nuestra forma de obtener recursos para la existencia. 


\section{Bibliografía}

Castillo M., Félix et al. 2016, La Cultura Sapara en Peligro ¿El Sueño es Posible? La lucha de un pueblo por su supervivencia frente a la explotación petrolera, Terra Mater, la Nación Sapara del Ecuador y NAKU, Quito, en: http://terramater.ec/wp-content/uploads/2017/01/libro-sapara.pdf

Moya, A. 2007 Los Aritiakus, hijos e hijas del mono colorado, Organización de las Naciones Unidas para la Educación, la Ciencia y la Cultura, UNESCO, Ecuador, en: http://unesdoc.unesco.org/ images/0016/001604/160494m.pdf

Sindicato Audiovisual (www.sindicatoaudiovisual.com) 